Robert Hermann $\cdot$ A. P. Laine $\cdot$ R. Veijola $\cdot$

T. Vahlberg • S. Simell · J. Lähde · O. Simell • M. Knip •

J. Ilonen

\title{
The effect of HLA class II, insulin and CTLA4 gene regions on the development of humoral beta cell autoimmunity
}

Received: 18 February 2005 / Accepted: 25 April 2005 / Published online: 16 July 2005

(C) Springer-Verlag 2005

\begin{abstract}
Aims/hypothesis: The aim of this study was to explore the contribution of genetic factors to the emergence of beta-cell-specific humoral autoimmunity. Subjects and methods: We analysed the effect of HLA class II, insulin (INS; -23 HphI variant) and cytotoxic T-lymphocyteassociated protein 4 (CTLA4 [+49 and CT60]) genes on the appearance of beta-cell-specific autoantibodies in a large population-based birth cohort recruited in Finland. Infants carrying increased risk HLA $D Q B 1$ genotypes were monitored for the appearance of autoantibodies (islet cell autoantibodies [ICA], insulin autoantibodies [IAA], glutamic acid decarboxylase autoantibodies [GADA] and islet antigen 2 antibodies [IA-2A]). Those who developed beta-
\end{abstract}

R. Hermann · A. P. Laine $\cdot$ R. Veijola $\cdot$ S. Simell $\cdot$ J. Lähde O. Simell $\cdot$ M. Knip · J. Ilonen

JDRF Centre for Prevention of Type 1 Diabetes in Finland, Turku, Finland

R. Hermann $(\bowtie) \cdot$ A. P. Laine $\cdot$ J. Ilonen

Department of Virology, University of Turku,

Kiinamyllynkatu 13 ,

20520 Turku, Finland

e-mail: robert.hermann@utu.fi

Tel.: +358-2-3337023

Fax: $+358-2-3337000$

R. Veijola

Department of Paediatrics, University of Oulu,

Oulu, Finland

T. Vahlberg

Department of Biostatistics, University of Turku,

Turku, Finland

S. Simell · O. Simell

Department of Paediatrics, University of Turku,

Turku, Finland

J. Lähde · M. Knip

Department of Paediatrics, Tampere University Hospital,

Tampere, Finland

M. Knip

Hospital for Children and Adolescents, University of Helsinki,

Helsinki, Finland cell-specific autoantibodies were studied $(n=574$, mean follow-up time: 4.9 years; range $0.5-9.3$ ). Results: IAA emerged at a higher rate in children with the $-23 \mathrm{HphI}$ AA INS genotype than in those carrying AT or TT variants (hazard ratio $2.1,95 \%$ CI 1.4-2.9, $p<0.001$ ). This effect of the INS locus was present in both HLA $D Q B 1$ risk groups. The appearance of IAA showed a strong association also with the HLA DRB1*0401 allele (hazard ratio $13.1,95 \%$ CI 1.8-93.4, $p<0.001)$. The development of IA-2A was also somewhat accelerated by the $D R B 1 * 0401$ variant $(p=0.03)$. Isolated ICA positivity was independent of the HLA and INS genotypes. None of the humoral immune markers showed association with the CTLA4 gene. Conclusions/interpretation: The INS and the DRBI loci appear to contribute to the pathogenesis of type 1 diabetes by initiating/modifying insulin-specific autoimmunity. The emergence of IAA represents a crucial step in the development of beta cell autoimmunity in young children, in whom the appearance of GADA and IA-2A is linked to IAA.

Keywords Autoimmune disease - Autoantibodies · CTLA4 - DQB1 - DRB1 - HLA - Insulin autoimmunity · Insulin gene $\cdot$ Type 1 diabetes

Abbreviations CTLA4: cytotoxic T-lymphocyteassociated protein 4/IDDM12 - DIPP: Type I Diabetes Prediction and Prevention project - GADA: glutamic acid decarboxylase autoantibodies - IAA: insulin autoantibodies - IA-2A: islet antigen 2 antibodies - ICA: islet cell antibodies - INS: insulin gene region/IDDM2 locus - JDFU: Juvenile Diabetes Foundation Units - RU: relative units - VNTR: variable number of tandem repeats

\section{Introduction}

Type 1 diabetes develops in genetically susceptible individuals as a result of immune-mediated damage of the pancreatic beta cells. Although cellular immunity is perceived to play a central role in the effector phase of islet 
destruction, a combination of humoral markers (islet cell autoantibodies [ICA], insulin autoantibodies [IAA], glutamic acid decarboxylase autoantibodies [GADA] and islet antigen 2 antibodies [IA-2A]) has proved to be a useful tool for monitoring the development of islet autoimmunity and for prediction of progression to clinical disease [1-4]. Although the association of certain HLA haplotypes with the appearance of IAA, GADA and IA-2A seems to be consistent in various studies [5-8], it is still unclear at what stage of the autoimmune process the HLA genes exert their effect.

Although the HLA gene region accounts for approximately half of the genetic disease susceptibility, a number of other 'minor' loci also contribute [9-11]. The insulin gene (INS; IDDM2) and the cytotoxic T-lymphocyteassociated protein 4 (CTLA4) gene regions (IDDM12) are considered as confirmed non-HLA disease susceptibility loci [12-16]. Short (class I) alleles of the insulin gene 5' variable number of tandem repeats (VNTR) are associated with increased type 1 diabetes susceptibility fitting an allele dosage model, while long class III alleles confer protection [17]. In the CTLA4 region, a number of variants, like the $+49 \mathrm{~A} / \mathrm{G}$, have shown disease association in various ethnic groups, while the CT60 polymorphism was identified as a candidate causative disease variant $[14-16,18]$.

Our knowledge of the effect of the insulin and CTLA4 gene regions on type 1 diabetes-associated humoral autoimmunity is limited and controversial. An early study observed no association between the INS VNTR genotype and insulin-specific cellular and humoral autoimmunity [19], while class I alleles of the VNTR were found to contribute to the emergence of IAA in a larger case-control comparison [7]. It has also been suggested that the INS locus confers increased disease risk only in subjects with moderate-risk HLA genotypes [20]. However, recent studies have suggested that the INS polymorphism could modify progression to clinical disease among individuals with both high-risk and low-risk HLA genotypes [21-23]. Data on the effect of the CTLA4 gene region on beta cell autoimmunity are similarly ambiguous. The CTLA4-3'(AT)n microsatellite and the $+49 \mathrm{~A} / \mathrm{G}$ polymorphism showed no association with humoral autoimmunity in Swedish and Belgian cohorts, whereas IA-2A showed association with the $\mathrm{G}$ allele of the $+49 \mathrm{~A} / \mathrm{G}$ polymorphism in a Japanese study $[7,24,25]$.

In the Type I Diabetes Prediction and Prevention project (DIPP) currently underway in Finland, population-based genetic screening for type 1 diabetes-associated HLA $D Q B 1$ genotypes is performed in newborn infants followed by continuous monitoring of beta-cell-specific humoral autoimmunity in the risk cohort [26]. The aim of this study was to analyse the effect of the HLA class II, INS-VNTR and CTLA4 loci on the development of diabetes-associated autoantibodies in an early phase of the autoimmune process.

\section{Subjects and methods}

\section{Study design}

In the framework of the DIPP study, screening for HLAconferred susceptibility to type 1 diabetes is performed in all infants born in three university hospitals in Finland, i.e. Turku, Tampere and Oulu [26]. All infants $(n>9,000$ by May 2004) with risk HLA $D Q B 1$ genotypes $(D Q B 1 * 02 /$ *0302, DQB1*0302/X, DQA1*05-DQB1*02/Y, where $x \neq D Q B 1 * 02, D Q B 1 * 0301, D Q B 1 * 0602, y \neq D Q A 1 * 0201-$ $D Q B 1 * 02, D Q B 1 * 0301, * 0302, * 0602$ or $* 0603)$ were followed and sampled at 3-12-month intervals as described [26]. ICA were measured in all serum samples and, if positive, IAA, GADA and IA-2A were tested in all serum samples available from that ICA-positive subject. In this study, we analysed HLA class II, INS and CTLA4 genotypes in relation to humoral islet autoimmunity. The local ethics committees had approved the study and informed consent was obtained from the parents of the participating subjects. All study subjects were of Finnish ethnic origin. The study was conducted according to the principles of the Declaration of Helsinki.

\section{Study population}

Antibody-positive children All children who had developed ICA by May $2004\left(n=574,180\right.$ with the $D Q B 1^{* 02 /}$ $D Q B 1^{*} 0302$ high-risk, 368 with the $D Q B 1 * 0302 / X$ and 26 with the $D Q A 1 * 05-D Q B 1 * 02 / Y$ moderate-risk genotypes, $53.5 \%$ boys) were tested for autoantibodies (IAA, GADA and IA-2A) and for genetic markers (HLA DRB1$D Q A 1-D Q B 1, I N S-23 \mathrm{HphI}$ as well as CTLA4+49 and CT60 polymorphisms). At the time of this analysis the mean $( \pm \mathrm{SD})$ follow-up time in the $D Q B 1 * 02 / D Q B 1 * 0302$ and $D Q B 1^{*} 0302 / X$ groups was $4.9 \pm 2.2$ years (range 0.5 9.3 years), while it was somewhat shorter in those carrying the $D Q B 1^{*} 02 / y$ combinations (mean $3.9 \pm 1.4$ years, range 0.5-6.1 years). By May 2004, 74 of these children (12.9\%) had progressed to clinical type 1 diabetes diagnosed according to the WHO criteria.

Healthy control children without antibodies The control group comprised ICA-negative healthy children, who were randomly selected, but matched for sex, age and place of birth, from the entire DIPP birth cohort $(n=2,563,52.9 \%$ boys, mean age $3.6 \pm 1.5$ years). HLA $D Q B 1$ typing was done in all controls according to the DIPP screening scheme [26]. DQA1 typing was performed in individuals with $D Q B 1 * 02$, while $D Q B 1 * 0302$-positive children were $D R B 1 * 04$ subtyped. The INS and CTLA4 gene polymorphisms were typed as described below. This group was used for comparisons in the analysis of genetic effects on the appearance of ICA. 
Methods

Genotyping The methods and the resolutions for the HLA $D Q B 1$ 'full house' for the $D Q A 1$ and $D R B 1 * 04$ typing were described earlier [27-29]. The INS -23 HphI and the CTLA4+49 polymorphisms were analysed using PCR and a lanthanide-labelled oligonucleotide hybridisation method $[27,30]$. (CTLA4+49 A probe: 5'-Terbium-TGGCTACCAGGA-3'; G probe: 5'-Terbium-GGCTGCCAGGA-3'; -23 HphI T probe: 5'-Europium-CTGTCTCCCAGA-3'; A probe: 5'-Terbium-CTGTCACCCAGA-3'). CT60 was genotyped using minisequencing (SnuPe Kit; GE Healthcare-formerly Amersham Biosciences-Chalfont St Giles, UK) and a MegaBACE 1000 sequencer (GE Healthcare).

Autoantibody assays The antibody assay parameters that apply have been described in detail [4]. The detection limit for ICA was $2.5 \mathrm{JDFU}$ (sensitivity 100\%, specificity 98\%). IAA titres were quantified with a microassay $[31,32]$. GADA and IA-2A were measured using specific radioligand assays $[33,34]$. The cut-off limits for IAA, GADA and IA-2A positivity were $1.56,5.36$ and 0.43 RU, respectively, representing the 99th percentiles in a series comprising more than 370 non-diabetic Finnish children and adolescents. The disease sensitivities of the IAA, GADA and IA-2A assays were 44,82 , and $62 \%$, respectively, while the specificity values were 98,98 and $100 \%$, respectively, based on the 2002 Diabetes Autoantibody Standardisation Programme (DASP) Workshop.

Statistical analysis Kaplan-Meier survival analysis was applied to evaluate genetic effects on the appearance of various autoantibodies. Differences between the survival curves were tested with log-rank test. Cox regression was employed to dissect the effect of various factors (antibody status, genotypes) on autoantibody-free survival. Longitudinal data of all antibody measurements that were available for the cohort of antibody-positive children were analysed using a linear mixed model where age and group were used as fixed factors and subject as a random factor to account for correlation between repeated measurements. Logarithmic transformation of the antibody titres was applied to normalise their distribution. In the comparison of HLA, INS and CTLA4 genotype frequencies between ICApositive children and ICA-negative controls, chi-square statistics with Yates' correction were used. To compare the highest autoantibody titres detected during the whole follow-up period in children carrying different genotypes, the Kruskal-Wallis and the Mann-Whitney $U$-tests were used. In multiple comparisons, Bonferroni corrections were used (shown as $p_{\mathrm{c}}$ ); $p$ values lower than 0.05 were considered statistically significant. All statistical analyses were done using SPSS for Windows (version 11.0.1; SPSS, Chicago, IL, USA).

\section{Results}

HLA $D R B 1-D Q A 1-D Q B 1$ and the appearance of autoantibodies

The results of the Kaplan-Meier survival analysis on the emergence of autoantibodies in the various $D Q B 1$ genotype groups are shown in Table 1 . The median values for the antibody-free survival could not be calculated in most cases, since the cumulative antibody frequencies were usu-
Table 1 Cumulative frequencies of autoantibodies and antibody-free survival in children carrying various HLA $D Q B 1$ and $D R B 1$ genotypes

\begin{tabular}{|c|c|c|c|c|}
\hline $\begin{array}{l}\text { Autoantibody } \\
\text { analysed }\end{array}$ & $\begin{array}{l}\text { HLA genotype or } \\
D R B 1 * 04 \text { allele }\end{array}$ & $\begin{array}{l}\text { Cumulative frequencies } \\
\text { of antibody }(\%)\end{array}$ & $\begin{array}{l}\text { Antibody-free survival in } \\
\text { years (mean }[95 \% \mathrm{CI}] \text { ) }\end{array}$ & $p$ value $^{\mathrm{a}}$ \\
\hline IAA & $\begin{array}{l}D Q B 1 * 02 / * 0302 \\
D Q B 1 * 0302 / X^{\mathrm{b}} \\
D Q A 1 * 05- \\
D Q B 1 * 02 / Y^{\mathrm{c}}\end{array}$ & $\begin{array}{l}54.2 \\
40.5 \\
16.6\end{array}$ & $\begin{array}{l}5.7(5.1-6.2) \\
6.5(6.1-6.9) \\
5.3(4.6-6.0)\end{array}$ & 0.012 \\
\hline GADA & $\begin{array}{l}D Q B 1 * 02 / * 0302 \\
D Q B 1 * 0302 / X \\
D Q A 1 * 05- \\
D Q B 1 * 02 / Y\end{array}$ & $\begin{array}{l}50.6 \\
37.9 \\
34.1\end{array}$ & $\begin{array}{l}6.0(5.5-6.6) \\
7.0(6.6-7.3) \\
4.7(4.0-5.6)\end{array}$ & 0.011 \\
\hline IA-2A & $\begin{array}{l}D Q B 1 * 02 / * 0302 \\
D Q B 1 * 0302 / X \\
D Q A 1 * 05- \\
D Q B 1 * 02 / Y\end{array}$ & $\begin{array}{l}60.6 \\
37.2 \\
10.2\end{array}$ & $\begin{array}{l}6.4(5.9-6.9) \\
7.0(6.7-7.4) \\
5.7(5.3-6.1)\end{array}$ & 0.017 \\
\hline IAA & $\begin{array}{l}D R B 1^{*} 0401^{\mathrm{d}} \\
D R B 1 * 0404 \\
D R B 1 * 0403\end{array}$ & $\begin{array}{r}52.1 \\
37.0 \\
6.1\end{array}$ & $\begin{array}{l}5.6(5.2-6.0) \\
7.1(6.5-7.5) \\
8.2(7.7-8.8)\end{array}$ & $<0.0001$ \\
\hline GADA & $\begin{array}{l}D R B 1 * 0401 \\
D R B 1 * 0404 \\
D R B 1 * 0403\end{array}$ & $\begin{array}{l}46.5 \\
29.3 \\
10.1\end{array}$ & $\begin{array}{l}6.2(5.8-6.6) \\
7.3(6.8-7.8) \\
7.8(7.0-8.7)\end{array}$ & 0.0007 \\
\hline IA-2A & $\begin{array}{l}D R B 1 * 0401 \\
D R B 1 * 0404 \\
D R B 1 * 0403\end{array}$ & $\begin{array}{r}50.3 \\
36.2 \\
0.0\end{array}$ & $\begin{array}{l}6.3(5.9-6.7) \\
7.7(7.2-8.2) \\
-\end{array}$ & $<0.0001$ \\
\hline
\end{tabular}

All children tested repeatedly positive for ICA. Children carrying the antibody analysed in the comparisons could also carry additional molecular autoantibodies

${ }^{a}$ Log-rank test, $d f=2$ for all $p$ values

${ }^{x} \neq D Q B 1 * 02, * 0301, * 0602$

c $y \neq D Q B 1 * 0302, * 0301, * 0603$, *0602, DQA1*0201-DQB1*02

${ }^{\mathrm{d}} D R B 1 * 04$ subtypes carry $D Q B 1 * 0302$ on the same haplotype, the second haplotype is $x$ or $D R 3 / D R 7-D Q B 1 * 02$ 
ally lower than $50 \%$; therefore the mean values for antibody-free survival are shown in the tables. The cumulative frequencies of IAA were higher and antibody-free survival was shorter among children with the $D Q B 1 * 02 / * 0302$ genotype compared with those in the $D Q B 1^{*} 0302 / X$ group. The lowest cumulative IAA frequency was observed in the $D Q A 1^{*} 05-D Q B 1^{*} 02 / Y$ group. Similarly, IA-2A appeared at a higher rate among children with the $D Q B 1^{*} 02 /$ $* 0302$ and $D Q B 1 * 0302 / X$ combinations than in those carrying the $D Q A 1 * 05-D Q B 1 * 02 / Y$. Also GADA developed at the highest frequency in the $D Q B 1^{*} 02 / * 0302$ group, while children with the $D Q B 1^{*} 0302 / X$ or $D Q A 1^{*}$ $05-D Q B 1 * 02 / Y$ combinations had similar cumulative frequencies of GADA.

A strong differential effect of the various $D R B 1^{*} 04$ alleles on the emergence of autoantibodies was detected in children carrying the $D R 4-D Q B 1 * 0302$ haplotype (Table 1). In the Cox regression, analysis, the unadjusted hazard ratios for developing IAA in the $D R B 1 * 0401$ and *0404 groups were 13.1, (95\% CI: 1.8-93.4) and 6.8 (95\% CI: 1.2-49.2, $p<0.001$; reference allele: $D R B 1^{*} 0403$ ). The association of IAA with $D R 4$ subtypes remained significant in the Cox regression analysis also after adjusting for the GADA and IA2A status (hazard ratios for $* 0401$ and for $* 0404$ were 5.0 [95\% CI 2.1-36.2] and 3.3 [95\% CI 2.1-23.9], respectively, $p=0.017, d f=2$ ). Similarly, the effect of the $D R B 1^{*} 04$ alleles on the appearance of IA-2A remained significant after adjusting for the IAA and GADA status $(p=0.03, d f=2)$. No such independent $D R B 1^{*} 04$ effect was observed, however, on the appearance of GADA.

A quantitative effect of $D R B 1^{*} 04$ on IAA and IA-2A levels was detected when the peak antibody levels seen during follow-up were compared. Children with the $D R B 1^{*} 0401$ allele had higher antibody levels than those carrying the $D R B 1^{*} 0404$ allele ([median and interquartile range]: $D R B 1 * 0401$ group IAA: 16.7 [7.5-51.5] RU and IA-2A: 98.3 [28.5-120.8] RU DRB $1^{*} 0404$ group IAA: 8.7 [4.8-12.1] RU, $p_{\mathrm{c}}=0.02$; and IA-2A: 29.5 [2.0-99.7] RU, $p_{\mathrm{c}}=0.039$, respectively).

Table 2 Cumulative frequencies of autoantibodies and antibody-free survival in children carrying various insulin gene genotypes
To explore the effect of $D R B 1^{*} 04$ subtypes on the emergence of ICA, we compared the DRBI*04 allele frequencies in children who tested positive for ICA alone with those observed among the antibody-negative controls. There was no difference between the two groups (children testing positive for ICA only: DRB1*0401 57.9\%,*0404 $33.7 \%$, *0403 $6.7 \%$ vs controls $59.0,32.8$ and $7.2 \%$, respectively).

The insulin locus and the appearance of autoantibodies

Survival analysis of the effect of the insulin locus on the appearance of autoantibodies The cumulative frequency of IAA was higher and autoantibody-free survival was shorter in children with the INS -23 HphI AA genotype than in those carrying the AT or TT combinations (hazard ratio 2.1. [95\% CI: 1.4-2.9] $p<0.0001$; Table 2, Fig. 1a). The effect of the INS locus on the development of IAA seemed even stronger in those children where IAA appeared as the first antibody (hazard ratio: 2.5 [95\% CI 1.6-3.4] $p<0.00001)$. Similarly, the cumulative frequency of IAA was increased also in $-23 \mathrm{HphI}$ AA carrying subjects who tested negative for GADA or IA-2A (Table 2, Fig. 1b). Accordingly, in the Cox regression model the effect of INS was significant after adjusting for the GADA and IA-2A carrier status (adjusted hazard ratio for the appearance of IAA in the $-23 \mathrm{HphI}$ AA group was 1.7 [95\% CI 1.2-2.4] reference: AT/TT genotype, $p=0.004)$. The insulin locus had a clear effect on the development of IAA in all three $D Q B 1$ genotype groups (Fig. 1c, Table 3). In the Cox regression the effect of $-23 \mathrm{HphI}$ on IAA development adjusted for HLA $D Q B 1$ effects was highly significant (hazard ratio for the AA combination 2.1 [95\% CI 1.5-3.0], $p<0.0001)$.

Similarly, the effect of the INS locus on development of IAA was present both in the $D R B 1 * 0401$ and *0404 subtype categories (Table 3 ) (hazard ratio for the $-23 \mathrm{HphI}$ AA genotype adjusted for the DRB1*04: 2.0 [95\% CI 1.4 2.9], $p<0.0001)$.

\begin{tabular}{|c|c|c|c|c|c|}
\hline $\begin{array}{l}\text { Autoantibody } \\
\text { analysed }\end{array}$ & $\begin{array}{l}\text { Other } \\
\text { autoantibodies }\end{array}$ & $\begin{array}{l}-23 \mathrm{HphI} \\
\text { genotype }\end{array}$ & $\begin{array}{l}\text { Cumulative } \\
\text { frequencies of } \\
\text { antibodies (\%) }\end{array}$ & $\begin{array}{l}\text { Antibody-free survival in } \\
\text { years (mean }[95 \% \mathrm{CI}] \text { ) }\end{array}$ & $p$ value $^{\mathrm{a}}$ \\
\hline \multirow[t]{4}{*}{ IAA } & GADA+/-; & $\mathrm{AA}$ & 49.6 & $5.9(5.5-6.3)$ & \multirow[t]{2}{*}{$<0.0001$} \\
\hline & $\begin{array}{l}\mathrm{IA}-2 \mathrm{~A}+/- \\
\mathrm{ICA}+(n=574)\end{array}$ & $\mathrm{AT} / \mathrm{TT}$ & 30.3 & $7.4(6.9-7.9)$ & \\
\hline & GADA-; IA2A-; & AA & 18.9 & $8.1(7.7-8.5)$ & \multirow[t]{2}{*}{0.02} \\
\hline & $\mathrm{ICA}+(n=352)$ & $\mathrm{AT} / \mathrm{TT}$ & 9.0 & $8.6(8.2-8.9)$ & \\
\hline \multirow[t]{4}{*}{ GADA } & $\mathrm{IAA}+; \mathrm{IA} 2 \mathrm{~A}+/-;$ & AA & 79.8 & $3.7(3.2-4.2)$ & \multirow[t]{2}{*}{0.65} \\
\hline & $\mathrm{ICA}+(n=218)$ & $\mathrm{AT} / \mathrm{TT}$ & 77.9 & $3.8(2.7-4.8)$ & \\
\hline & IAA-; IA $2 \mathrm{~A}+/-$; & AA & 19.9 & $8.4(8.1-8.7)$ & \multirow[t]{2}{*}{0.70} \\
\hline & $\mathrm{ICA}+(n=356)$ & $\mathrm{AT} / \mathrm{TT}$ & 16.5 & $8.3(7.9-8.7)$ & \\
\hline \multirow[t]{4}{*}{ IA-2A } & $\mathrm{IAA}+; \mathrm{GADA}+/-$; & $\mathrm{AA}$ & 82.1 & $3.8(3.4-4.3)$ & \multirow[t]{2}{*}{0.81} \\
\hline & $\mathrm{ICA}+(n=218)$ & AT/TT & 83.6 & $4.2(3.2-4.2)$ & \\
\hline & $\mathrm{IAA}-; \mathrm{GADA}+/-;$ & $\mathrm{AA}$ & 13.5 & $8.8(8.5-9.0)$ & \multirow[t]{2}{*}{0.72} \\
\hline & $\mathrm{ICA}+(n=356)$ & AT/TT & 19.0 & $8.7(8.4-8.9)$ & \\
\hline
\end{tabular}

${ }^{a}$ Log-rank test 
Fig. 1 Survival analysis of the effect of the insulin locus on the appearance of insulin autoantibodies (IAA). a Cumulative frequencies of IAA in children carrying different insulin gene $-23 \mathrm{HphI}$ genotypes. The cumulative frequency of IAA was higher in the AA group than in the AT/TT group $(p<0.0001)$. b Cumulative frequencies of IAA in GADA- and IA-2Anegative children carrying different insulin gene $-23 \mathrm{HphI}$ genotypes. The cumulative frequency of IAA was higher in the AA group than in the AT/TT group $(p=0.02)$. Key $(\mathbf{a}, \mathbf{b})$ : solid line, subjects with the AA variant; dotted line, subjects carrying AT or TT combinations. c Cumulative frequencies of IAA in children carrying different HLA DQBI-INS-(-23)HphI combined genotypes. Key: bold dashed line, children with HLA $D Q B 1 * 02 / * 0302-I N S-(-23)$

HphI-AA; bold dotted line, individuals carrying $H L A$

$D Q B 1 * 02 / * 0302-I N S-(-23)$

$\mathrm{HphI-AT/TT;} \mathrm{solid} \mathrm{line,} \mathrm{subjects}$ with the HLA $D Q B 1^{*} 0302 / X$ INS- $(-23) \mathrm{HphI}-\mathrm{AA}$; thin dotted line, the $H L A D Q B 1 * 0302 / X$ INS- $(-23) \mathrm{HphI}-\mathrm{AT} / \mathrm{TT}$ group. IAA frequencies were higher in the AA groups in both HLA categories $(p=0.0002 ; d f=3)$
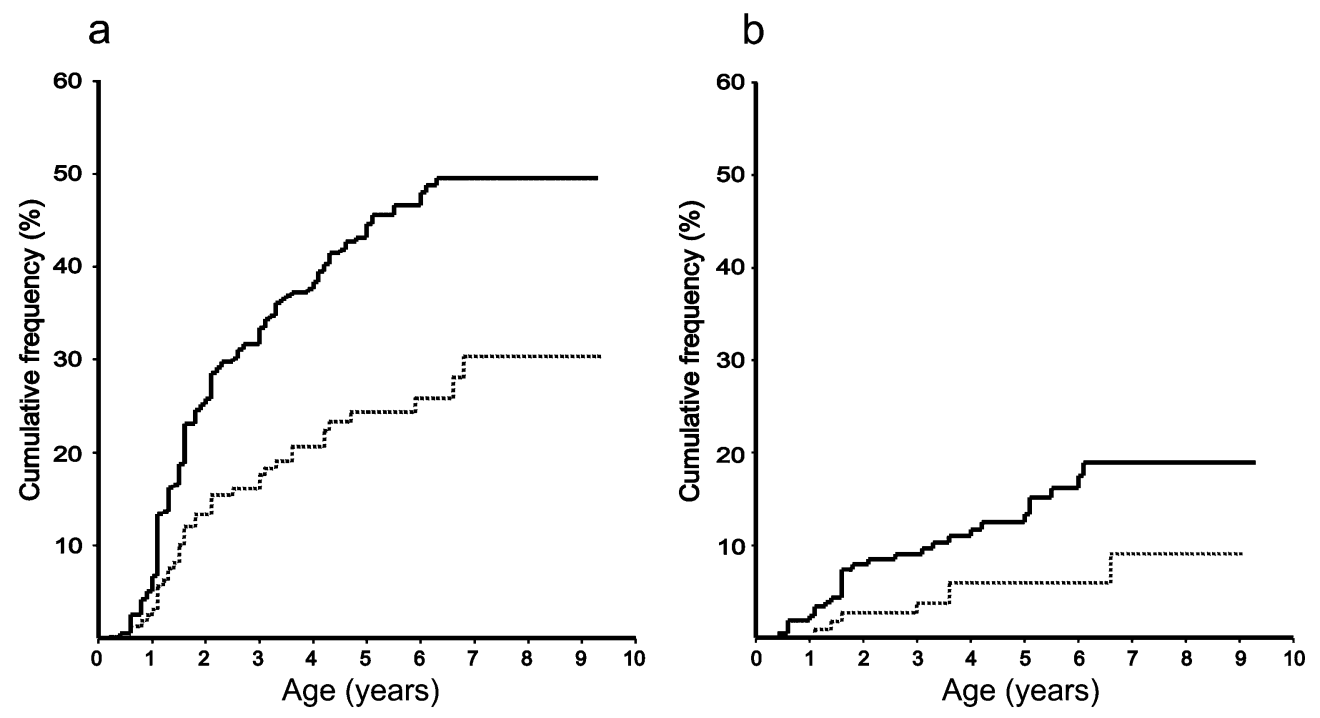

C

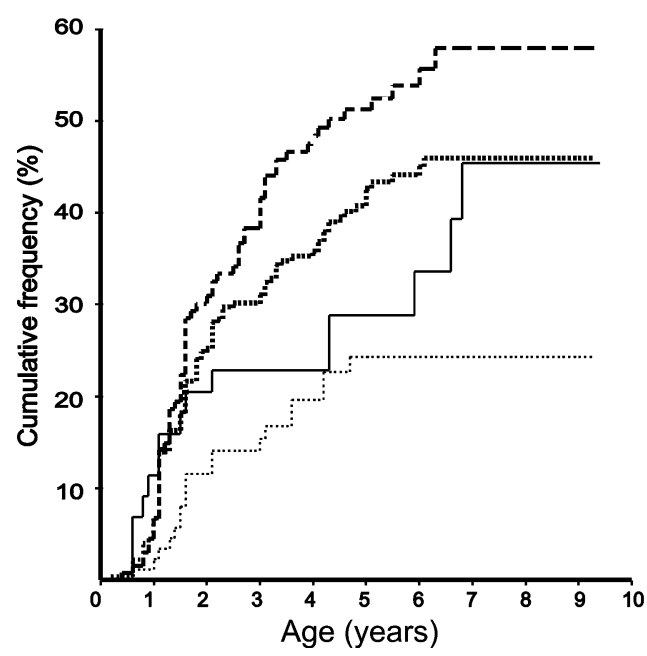

Cumulative frequencies of GADA and antibody-free survival showed differences between the INS $-23 \mathrm{HphI}$ AA and AT/TT genotype groups in the Kaplan-Meier analysis when the autoantibody data set was analysed unstratified (AA group $46.0 \%$ vs AT/TT group $31.8 \%$, and 6.4 years [95\% CI 6.1-6.8] vs 7.3 years [95\% CI 6.7-7.8], respectively, $\log$-rank $5.5, p=0.02$; Fig. 2a). However, no effect of the INS polymorphism was detected on the appearance of GADA when children were stratified according to their IAA status (Table 2, Fig. 2b). Importantly, GADA appearance was strongly influenced by IAA status, as IAA-positive children developed GADA at a higher rate than IAA-negative children (hazard ratio $12.5[95 \%$ CI 8.6-18.1], $p<0.0001$ ).

Similarly, in the unstratified data set the emergence of IA-2A appeared to be influenced by the $-23 \mathrm{HphI}$ variant (cumulative frequency in the AA group: 43.6 vs $35.9 \%$ in the AT/TT group; median antibody-free survival: 6.7 years [95\% CI 6.3-7.1] vs 7.7 years [95\% CI 7.2-8.1], respectively; log-rank 9.8, $p=0.002$; Fig. 2c). However, no effect of the INS locus was observed when the cohort was stratified according to the IAA status (Table 2, Fig. 2d). Emer-
Table 3 Cumulative frequencies of insulin autoantibodies (IAA) and IAA-free survival in children carrying various HLA $D Q B 1$ and $D R B 1$ and insulin gene genotypes

\begin{tabular}{lllll}
\hline $\begin{array}{l}\text { HLA } \\
\text { genotype }\end{array}$ & $\begin{array}{l}-23 \\
\text { HphI } \\
\text { genotype IAA }(\%)\end{array}$ & $\begin{array}{l}\text { Cumulative } \\
\text { frequency of }\end{array}$ & $\begin{array}{l}\text { IAA free survival } \\
\text { in years (mean } \\
[95 \% \mathrm{CI}])\end{array}$ & $p$ value $^{\mathrm{a}}$ \\
\hline$D Q B 1^{* 02 /}$ & AA & 60.1 & $4.2(2.3-6.2)$ & $<0.0001$ \\
$* 0302$ & AT/TT & 39.1 & $7.0(5.9-8.0)$ & $(d f=5)$ \\
$D Q B 1^{*} 0302 /$ & AA & 45.4 & $6.1(5.6-6.6)$ & \\
$X^{\mathrm{b}}$ & AT/TT & 24.7 & $7.4(6.8-8.0)$ & \\
$D Q B 1^{*} 02 / Y^{\mathrm{c}}$ & AA & 19.2 & $5.1(4.2-6.1)$ & \\
& AT/TT & 14.3 & $3.8(3.2-4.4)$ & \\
$D R B 1^{* 0401}$ & AA & 57.4 & $4.5(3.2-5.8)$ & $<0.0001$ \\
& AT/TT & 39.4 & $6.5(5.8-7.2)$ & $(d f=3)$ \\
$D R B 1^{*} 0404$ & AA & 42.8 & $6.6(5.9-7.3)$ & \\
& AT/TT & 16.7 & $8.5(7.8-9.2)$ & \\
\hline
\end{tabular}

${ }^{\mathrm{a}}$ Log-rank test

${ }^{\mathrm{b}} x \neq D O B 1 * 02, * 0301, * 0602$

c $y \neq D Q B 1 * 0302, * 0301, * 0603, * 0602, D Q A 1 * 0201-D Q B 1 * 02$

${ }^{d} D R B 1 * 04$ subtypes carry $D Q B 1^{*} 0302$ on the same haplotype, the second haplotype is $x$ or $D R 3 / D R 7-D Q B 1^{*} 02$ 
Fig. 2 Survival analysis of the effect of the insulin locus on the appearance of GADA and IA-

2A. Solid lines, subjects with the AA variant; dotted lines, individuals carrying AT or TT combinations. a Cumulative frequencies of GADA in children carrying different insulin gene $-23 \mathrm{HphI}$ genotypesunstratified data set. GADA frequencies were higher in the AA group $(p=0.02)$. Cumulative frequencies (b) of GADA in IAA-negative children with different $-23 \mathrm{HphI}$ genotypes $(p=0.70)$. Cumulative frequencies (c) of IA-2A in children carrying different insulin gene $-23 \mathrm{HphI}$ genotypes-unstratified data set. IA-2A frequencies were higher in the AA group $(p=0.002)$. d Cumulative frequencies of IA-2A in IAAnegative children carrying different insulin gene $-23 \mathrm{HphI}$ genotypes $(p=0.72)$
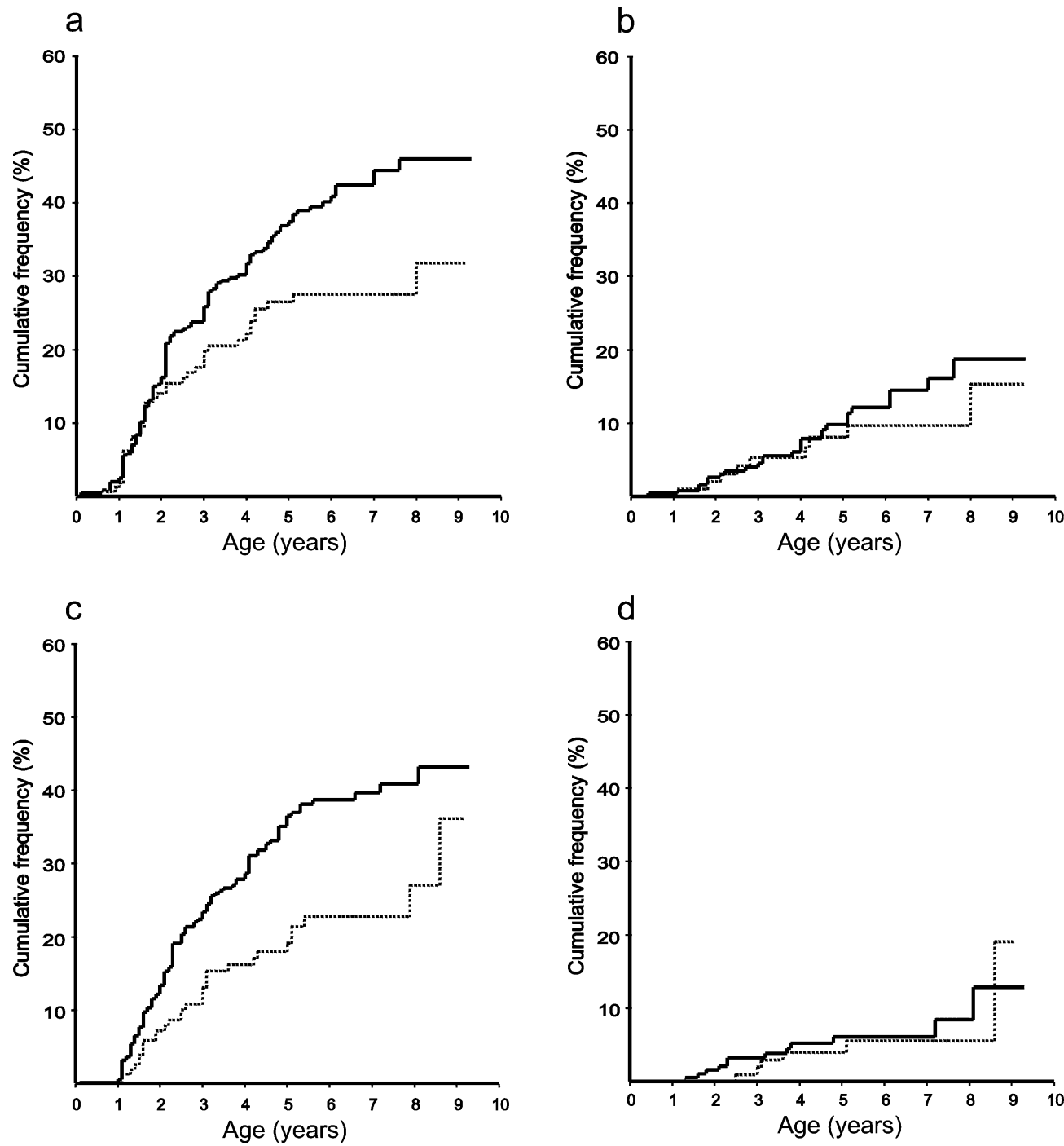

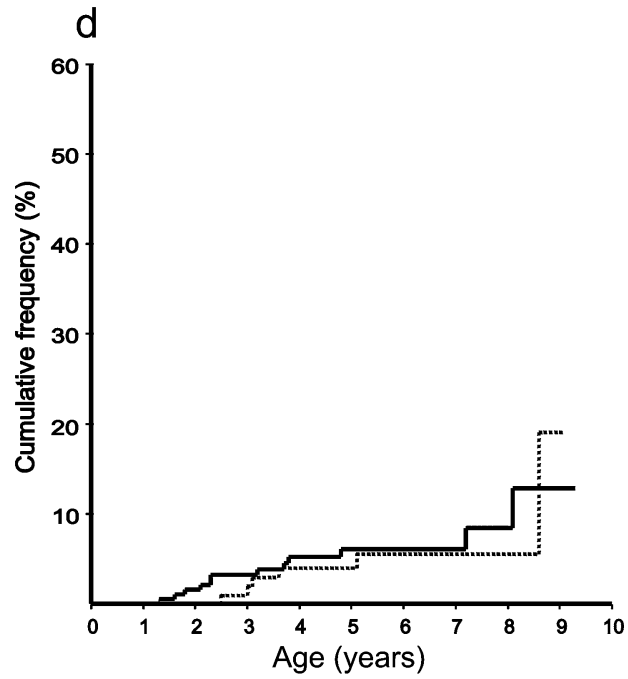

gence of GADA was higher in IAA positive children than in those without IAA (hazard ratio 20.9 [95\% CI 13.133.0] $p<0.0001)$.

INS effects on IAA levels The peak IAA levels detected during follow-up were compared between groups of children carrying different INS genotype. Subjects with the -23 HphI AA variant had higher IAA levels than those with AT or TT (AA: 15.3 [6.9-46.6] RU; AT: 13.2 [4.036.8] RU; TT: 7.5 [4.6-18.5] RU, $p_{\mathrm{c}}=0.02, d f=2$; Fig. 3a). Similarly, IAA titres were observed to be higher in both HLA categories in children with the $-23 \mathrm{HphI}$ AA genotype compared with those who had AT or TT $\left(D Q B 1^{*} 02 /\right.$ *0302-HphI AA 20.5 [6.9-54.3] RU versus AT/TT 13.1 [5.7-38.3] RU; $D Q B 1 * 0302 / X$ - HphI AA 13.2 [6.1-52.6] $\mathrm{RU}$ vs AT/TT 8.7 [3.4-22.8] RU, $p_{\mathrm{c}}=0.007, d f=3$; correction factor $=2$; Fig. $3 b$ ). In the linear mixed model analysis we used all antibody measurements from each child to estimate the difference in the antibody status between the various genotype groups. The INS locus showed a clear gene dosage effect on IAA status. The IAA levels in subjects carrying $-23 \mathrm{HphI}$ AA and AT variants were higher than in those with TT (estimated average difference between AA and TT: 7.3 [95\% CI 5.7-10.6] RU; between AA and AT/TT: 2.4 [95\% CI: 0.4-5.1] RU; $p=0.0005$ ).

The CTLA4 gene polymorphisms and the appearance of autoantibodies

No effect of the CTLA4+49 or CT60 polymorphisms on the emergence of islet-specific autoantibodies was observed in this study (data not shown).

\section{Discussion}

We analysed the effect of the insulin, the CTLA4 and the HLA DRB1-DQA1-DQB1 genes on the development of humoral beta cell autoimmunity in a large populationderived Finnish birth cohort with increased HLA DQB1conferred genetic risk for type 1 diabetes (the DIPP study) [26]. The selection criteria for the study cohort comprising ICA-positive children limited our possibilities to analyse 
a

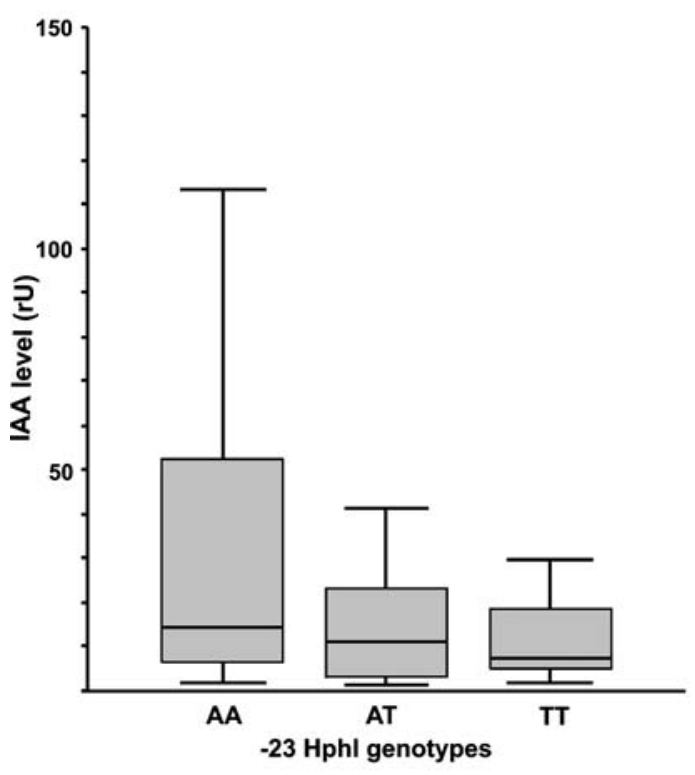

Fig. 3 Insulin autoantibody (IAA) levels in children carrying various insulin gene $(-23) \mathrm{HphI}$ genotypes. The box plots represent the medians (thick solid line) and the interquartile ranges, while error bars mark the lowest and highest values that are not outliers. a IAA levels were higher in children with the IDDM2 -23 HphI AA

thoroughly the HLA effects, since most study subjects carried the $D R 4-D Q B 1^{*} 0302$ haplotype, however, the contribution of the insulin and CTLA4 loci to the diseasespecific autoimmune phenomena could be fully explored. We also analysed the effect of $D R B 1^{*} 04$ alleles on the $D R 4-D Q B 1 * 0302$ haplotypes, since they confer different degrees of disease susceptibility in the Finnish population, as the $D R B 1^{*} 0401$ allele is associated with higher risk than the $D R B 1 * 0404$ variant and the $D R B 1 * 0403$ allele is protective $[28,35]$. At the INS locus the $-23 \mathrm{HphI}$ polymorphism was used as genetic risk marker, where the A alleles are in strong linkage disequilibrium with the $5^{\prime}$ INS VNTR class I susceptibility variants and the $\mathrm{T}$ alleles are linked with the protective class III alleles [12, 21]. The wellcharacterised CTLA4+49 and CT60 polymorphisms were chosen as disease markers at the IDDM12 locus [14, 16].

This is the first population-based study demonstrating that the INS locus affects the emergence of humoral beta cell autoimmunity and it provides strong evidence that INS directly influences humoral insulin-specific autoimmunity. A number of findings support this observation. Firstly, IAA emerged at a higher rate in children carrying the $-23 \mathrm{HphI}$ AA genotype compared with those who had AT or TT variants. This effect appeared to be even more pronounced in those infants who developed IAA as their first antibody reactivity. These observations strongly support the importance of the INS locus in the initiation of the autoimmune process. Secondly, a gene dosage effect of the INS locus on the appearance of IAA was detected, as the autoantibody titre was proportional to the number of INS susceptibility alleles. Importantly, the INS locus influenced

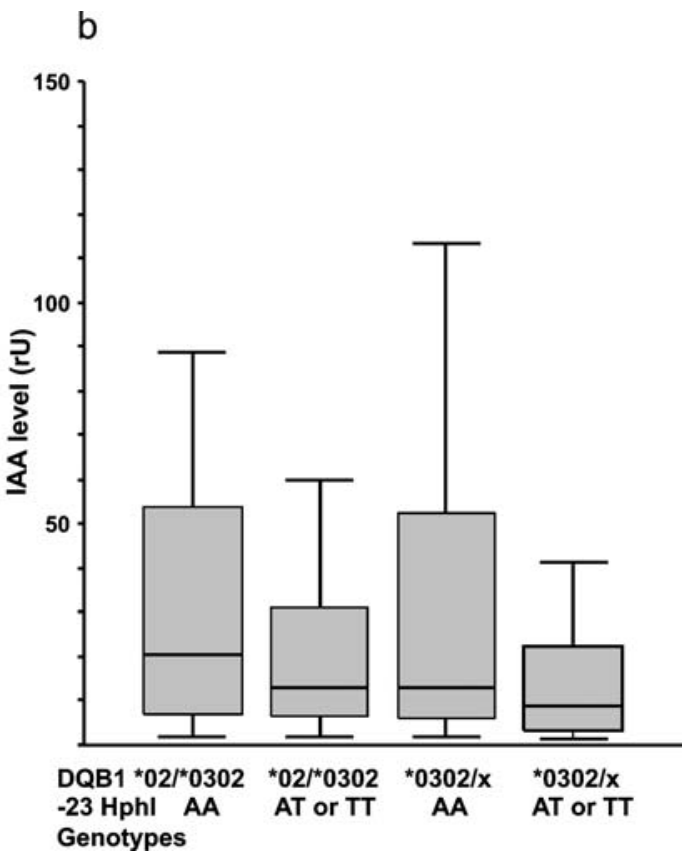

risk genotype than in those with AT or TT $\left(p_{\mathrm{c}}=0.005, d f=2\right)$. b Both in the $D Q B 1 * 02 / 0302$ and $D Q B 1^{*} 0302 / X$ groups IAA levels were higher in children with the $-23 \mathrm{HphI}$ AA genotype than in those carrying AT or TT variants $\left(p_{\mathrm{c}}=0.007, d f=3\right.$; correction factor $=2$ )

the development of IAA in all three HLA risk groups. Although the INS locus is associated with disease risk, the effect of INS on the emergence of IAA seems to be a genuine one, since IAA as such are not associated with particularly high diabetes risk $[1,4,36]$.

The association of IAA with the risk INS genotype is supported by observations made in two other recent studies on patients with newly diagnosed type 1 diabetes and on first-degree relatives [7, 22]. Recently, a more preserved beta cell function in recent-onset cases was found in individuals with the INS VNTR class III allele compared with those carrying class I alleles [37]. These data are in line with the hypothesis proposing that the INS-VNTR has a role in the regulation of insulin gene transcription in the thymus and modulation of insulin-specific self tolerance $[38,39]$.

A positive association between IA-2A and GADA with the INS risk genotype was also implicated by the analysis of the unstratified data set; however, it is explained by the fact that the majority (81.7\%) of IA-2A and GADApositive children also had IAA. The lack of a primary association between IA-2A or GADA and INS was clearly shown by the Cox regression and also by the survival analysis in the data set stratified according to the IAA status (see Fig. 2). These data points to the existence of two different pathways that result in the emergence of GADA and IA-2A. In the 'INS-dependent' pathway, insulin autoimmunity plays a central role in the initiation of the disease process, while the appearance of GADA and IA-2A is linked to the presence of IAA, probably by antigen spreading. In IAA-negative individuals the initiation of 
beta cell autoimmunity and development of GADA and IA-2A are likely controlled by factors other than the INS locus.

In the analysis on the relation of HLA class II and betacell-specific autoantibodies, the association of IAA and IA-2A with the $D R 4-D Q B 1^{*} 0302$ haplotype was supported by our data as both antibodies developed at a higher rate in children carrying this haplotype compared with the $D Q A 1^{*} 05-D Q B 1^{*} 02 / Y$ group. In addition, children carrying the high-risk $D Q B 1 * 02 / * 0302$ genotype had higher positive seroconversion rates for these antibodies than those with the $D Q B 1^{*} 0302 / X$ combination. In the $D Q A 1^{*}$ $05-D Q B 1 * 02 / Y$ group, GADA were the most frequent autoantibody reactivity detected. These observations are in line with findings by ourselves and other groups that indicate that the two major disease-associated HLA class II haplotypes could mediate alternative, although probably related pathways in the emergence of beta-cell-specific autoimmunity [5-8].

Importantly, we detected a differential effect of $D R B 1^{*}$ 04 alleles present on the $D R 4-D Q B 1 * 0302$ haplotypes on the development of diabetes-related autoantibodies, where the $D R B 1^{*} 0401$ allele showed a considerably stronger effect on the emergence of IAA than the $D R B 1^{*} 0404$ variant, while the $D R B 1 * 0403$ allele almost completely blocked the appearance of antibodies. The absence of antibody response in children with $D R B 1^{*} 0403$ could be related to the peptide binding specificity of the encoded DR molecule that has been shown to share three-dimensional and electro-chemical properties with particular HLA-DQ heterodimers protective from type 1 diabetes [40]. In the Cox regression analysis, no effect of the $D R B 1 * 04$ subtypes was seen on the emergence of GADA, and the association of IA-2A with $D R B 1^{*} 0401$ was only marginally significant. We also showed here that the effect of the INS locus is independent of the $D R B 1^{*} 04$ variant. There are only limited published data on this issue. A previous Swedish study suggested that IA-2A were associated with $D R B 1^{*}$ 0401 [41], but otherwise possible links between the autoantibodies and the $D R B 1^{*} 04$ alleles have remained unexplored. Our data indicate that the $D R B 1^{*} 0401$ variant - which confers the highest disease risk in the Finnish population [35] - could play an important role in the initiation of the insulin-specific immune processes. In IAApositive subjects the development of GADA and IA-2A appear to be linked to IAA, therefore, this genetic variant could indirectly influence GAD and IA-2-related autoimmunity.

In the analysis of genetic effects on the appearance of ICA, survival analysis was not feasible to explore the contribution of $D R B 1^{*} 04$ haplotypes as those data were not available for the whole follow-up cohort ( $>9,000$ children). Therefore we compared frequencies of these haplotypes between children testing positive for ICA only (most of whom had ICA titres below 20 JDFU) and autoantibodynegative control children. No difference was seen in these comparisons. This and others' findings indicate that low ICA titres show no association with HLA, whereas children with multiple autoantibodies or high titres of ICA show a HLA genotype distribution resembling that seen in patients with type 1 diabetes [42-45]. This implies that the appearance of low-titre ICA alone may represent harmless immune phenomena unrelated to the diabetes-specific disease process. It is important to note, that HLA seem to influence the progression of the autoimmune process, as the protective $D Q B 1^{*} 0602$ allele prevents development of diabetes in ICA-positive subjects [46, 47].

In this study we could not see any effect of the CTLA4+ 49 and CT60 polymorphisms on type 1 diabetes-specific humoral autoimmunity. The findings were similarly negative in the Belgian and Swedish surveys, where the CTLA4 3' UTR (AT)n microsatellite was used as genetic marker [7, 24]. However, IA-2A and CTLA4+49 A/G were reported to be associated with type 1 diabetes in Japanese patients, but this observation might be secondary to the increased prevalence of autoimmune thyroid disease among the patients included in that study [25]. Our findings indicate that the two polymorphisms in the CTLA4 region studied have no major role in type 1 diabetes-related humoral autoimmunity, the statistical power of the analysis being more than $90 \%$ to detect a hazard ratio of $1.6 ; \alpha=0.05$. It has to be noted, that the effect of CTLA4 on type 1 diabetes susceptibility is very weak in the Finnish population (OR $<1.3$ for the +49 GG genotype; unpublished) and in that range the study had limited statistical power.

In conclusion, we propose that the insulin locus plays a central role in the initiation of the autoimmune process in IAA-positive individuals, while the appearance of GADA and IA-2A is a secondary phenomenon. In addition, the HLA DRB $1^{*} 0401$ variant also seems to have a role in the regulation of insulin autoimmunity. In IAA-negative individuals the development of GADA and IA-2A and progression to clinical disease is likely controlled by factors other than the INS locus.

Acknowledgements This study was supported by Juvenile Diabetes Research Foundation (JDRF grants No. 4-1998-274 and 4-1999731), JDRF/European Foundation for the Study of Diabetes/Novo Nordisk Focused Research Grant for Type 1 Diabetes, Novo Nordisk Foundation, Turku, Oulu and Tampere University Central Hospitals and Academy of Finland. We thank the entire DIPP study personnel, particularly Eija Nirhamo, Piia Nurmi, Jussi Mantere, Mia Karlson, Ritva Suominen, Terhi Laakso, Sirpa Anttila, Susanna Heikkilä, Riitta Päkkilä and Päivi Salmijärvi for their skilful technical assistance. We are most grateful to all DIPP study children and their families for their irreplaceable contribution.

\section{References}

1. Kulmala P, Savola K, Reijonen H et al (2000) Genetic markers, humoral autoimmunity, and prediction of type 1 diabetes in siblings of affected children. Diabetes 49:48-58

2. LaGasse JM, Brantley MS, Leech NJ et al (2002) Successful prospective prediction of type 1 diabetes in schoolchildren through multiple defined autoantibodies: an 8-year follow-up of the Washington State diabetes prediction study. Diabetes Care 25:505-511 
3. Ziegler AG, Hummel M, Schenker M, Bonifacio E (1999) Autoantibody appearance and risk for development of childhood diabetes in offspring of parents with type 1 diabetes: the 2-year analysis of the German BABYDIAB study. Diabetes 48:460-468

4. Kimpimaki T, Kulmala P, Savola K et al (2002) Natural history of beta-cell autoimmunity in young children with increased genetic susceptibility to type 1 diabetes recruited from the general population. J Clin Endocrinol Metab 87:4572-4579

5. Vandewalle CL, Falorni A, Lernmark A et al (1997) Associations of GAD65- and IA-2-autoantibodies with genetic risk markers in new-onset IDDM patients and their siblings. Diabetes Care 20:1547-1552

6. Sabbah E, Savola K, Kulmala P et al (1999) Disease-associated autoantibodies and HLA-DQB1 genotypes in children with newly diagnosed insulin-dependent diabetes mellitus (IDDM). Clin Exp Immunol 116:78-83

7. Graham J, Hagopian WA, Kockum I et al (2002) Genetic effects on age-dependent onset and islet cell autoantibody markers in type 1 diabetes. Diabetes 51:1346-1355

8. Genovese S, Bonfanti R, Bazzigaluppi E et al (1996) Association of IA-2 autoantibodies with HLA DR4 phenotypes in IDDM. Diabetologia 39:1223-1226

9. Nerup J, Pociot F (2001) A genomewide scan for type 1diabetes susceptibility in Scandinavian families: identification of new loci with evidence of interactions. Am J Hum Genet 69:1301-1313

10. Cox NJ, Wapelhorst B, Morrison VA et al (2001) Seven regions of the genome show evidence of linkage to type 1 diabetes in a consensus analysis of 767 multiplex families. Am J Hum Genet 69:820-830

11. Pociot F, McDermott MF (2002) Genetics of type 1 diabetes mellitus. Genes Immun 3:235-249

12. Bennett ST, Lucassen AM, Gough SC et al (1995) Susceptibility to human type 1 diabetes at IDDM2 is determined by tandem repeat variation at the insulin gene minisatellite locus. Nat Genet 9:284-292

13. Bell GI, Horita S, Karam JH (1984) A polymorphic locus near the human insulin gene is associated with insulin-dependent diabetes mellitus. Diabetes 33:176-183

14. Marron MP, Raffel LJ, Garchon HJ et al (1997) Insulindependent diabetes mellitus (IDDM) is associated with CTLA4 polymorphisms in multiple ethnic groups. Hum Mol Genet 6: $1275-1282$

15. Nistico L, Buzzetti R, Pritchard LE et al (1996) The CTLA-4 gene region of chromosome $2 \mathrm{q} 33$ is linked to, and associated with, type 1 diabetes. Belgian Diabetes Registry. Hum Mol Genet 5:1075-1080

16. Ueda H, Howson JM, Esposito L et al (2003) Association of the T-cell regulatory gene CTLA4 with susceptibility to autoimmune disease. Nature 423:506-511

17. Barratt BJ, Payne F, Lowe CE et al (2004) Remapping the insulin gene/IDDM2 locus in type 1 diabetes. Diabetes 53:18841889

18. Donner H, Rau H, Walfish PG et al (1997) CTLA4 alanine-17 confers genetic susceptibility to Graves' disease and to type 1 diabetes mellitus. J Clin Endocrinol Metab 82:143-146

19. Sarugeri E, Dozio N, Belloni C, Meschi F, Pastore MR, Bonifacio E (1998) Autoimmune responses to the beta cell autoantigen, insulin, and the INS VNTR-IDDM2 locus. Clin Exp Immunol 114:370-376

20. van der Auwera B, Schuit F, Lyaruu I et al (1995) Genetic susceptibility for insulin-dependent diabetes mellitus in Caucasians revisited: the importance of diabetes registries in disclosing interactions between HLA-DQ- and insulin gene-linked risk. J Clin Endocrinol Metab 80:2567-2573

21. Laine AP, Hermann R, Knip M, Simell O, Akerblom HK, Ilonen J (2004) The human leukocyte antigen genotype has a modest effect on the insulin gene polymorphism-associated susceptibility to type 1 diabetes in the Finnish population. Tissue Antigens 63:72-74
22. Walter M, Albert E, Conrad M et al (2003) IDDM2/insulin VNTR modifies risk conferred by IDDM1/HLA for development of type 1 diabetes and associated autoimmunity. Diabetologia 46:712-720

23. Motzo C, Contu D, Cordell HJ et al (2004) Heterogeneity in the magnitude of the insulin gene effect on HLA risk in type 1 diabetes. Diabetes 53:3286-3291

24. Van der Auwera BJ, Vandewalle CL, Schuit FC et al (1997) CTLA-4 gene polymorphism confers susceptibility to insulindependent diabetes mellitus (IDDM) independently from age and from other genetic or immune disease markers. The Belgian Diabetes Registry. Clin Exp Immunol 110:98-103

25. Abe T, Takino H, Yamasaki H et al (1999) CTLA4 gene polymorphism correlates with the mode of onset and presence of ICA512 Ab in Japanese type 1 diabetes. Diabetes Res Clin Pract 46:169-175

26. Kupila A, Muona P, Simell T et al (2001) Feasibility of genetic and immunological prediction of type I diabetes in a population-based birth cohort. Diabetologia 44:290-297

27. Sjoroos M, Iitia A, Ilonen J, Reijonen H, Lovgren T (1995) Triple-label hybridization assay for type-1 diabetes-related HLA alleles. Biotechniques 18:870-877

28. Nejentsev S, Sjoroos M, Soukka T et al (1999) Populationbased genetic screening for the estimation of Type 1 diabetes mellitus risk in Finland: selective genotyping of markers in the HLA-DQB1, HLA-DQA1 and HLA-DRB1 loci. Diabet Med 16:985-992

29. Laaksonen M, Pastinen T, Sjoroos M et al (2002) HLA class II associated risk and protection against multiple sclerosis-a Finnish family study. J Neuroimmunol 122:140-145

30. Haller K, Kisand K, Nemvalts V, Laine AP, Ilonen J, Uibo R (2004) Type 1 diabetes is insulin -2221 MspI and CTLA-4+49 A/G polymorphism dependent. Eur J Clin Invest 34:543-548

31. Ronkainen MS, Hamalainen AM, Koskela P, Akerblom HK, Knip M (2001) Pregnancy induces nonimmunoglobulin insulinbinding activity in both maternal and cord blood serum. Clin Exp Immunol 124:190-196

32. Williams AJ, Bingley PJ, Bonifacio E, Palmer JP, Gale EA (1997) A novel micro-assay for insulin autoantibodies. J Autoimmun 10:473-478

33. Savola K, Sabbah E, Kulmala P, Vahasalo P, Ilonen J, Knip M (1998) Autoantibodies associated with type I diabetes mellitus persist after diagnosis in children. Diabetologia 41:1293-1297

34. Savola K, Bonifacio E, Sabbah E et al (1998) IA-2 antibodiesa sensitive marker of IDDM with clinical onset in childhood and adolescence. Diabetologia 41:424-429

35. Hermann R, Turpeinen H, Laine AP et al (2003) HLA DR-DQencoded genetic determinants of childhood-onset type 1 diabetes in Finland: an analysis of 622 nuclear families. Tissue Antigens 62:162-169

36. Strebelow M, Schlosser M, Ziegler B, Rjasanowski I, Ziegler M (1999) Karlsburg type I diabetes risk study of a general population: frequencies and interactions of the four major type I diabetes-associated autoantibodies studied in 9419 schoolchildren. Diabetologia 42:661-670

37. Nielsen LB, Mortensen HB, Chiarelli F et al (2005) Impact of IDDM2 on disease pathogenesis and progression in children with newly diagnosed type 1 diabetes: reduced insulin antibody titers and preserved beta-cell function. Results from the Hvidore study group in childhood diabetes. 40th SSSD Meeting, Linköping, April 8-10, p41 (abstract)

38. Pugliese A, Zeller M, Fernandez A Jr et al (1997) The insulin gene is transcribed in the human thymus and transcription levels correlated with allelic variation at the INS VNTR-IDDM2 susceptibility locus for type 1 diabetes. Nat Genet 15:293-297

39. Vafiadis P, Bennett ST, Todd JA et al (1997) Insulin expression in human thymus is modulated by INS VNTR alleles at the IDDM2 locus. Nat Genet 15:289-292

40. Cucca F, Lampis R, Congia M et al (2001) A correlation between the relative predisposition of MHC class II alleles to type 1 diabetes and the structure of their proteins. Hum Mol Genet 10:2025-2037 
41. Sanjeevi CB, Hagopian WA, Landin-Olsson M et al (1998) Association between autoantibody markers and subtypes of DR4 and DR4-DQ in Swedish children with insulin-dependent diabetes reveals closer association of tyrosine pyrophosphatase autoimmunity with DR4 than DQ8. Tissue Antigens 51:281286

42. Boehm BO, Manfras B, Seissler J et al (1991) Epidemiology and immunogenetic background of islet cell antibody positive nondiabetic schoolchildren-Ulm-Frankfurt population study. Diabetes 40:1435-1439

43. Ilonen J, Sjöroos M, Reijonen H et al (1997) HLA-DQB1 genotypes associated with IDDM risk in healthy schoolchildren positive for GAD65 and islet cell antibodies. In: Charron D (ed) Genetic diversity of HLA. Functional and medical implications. Proceedings of the Twelfth International Histocompatibility Workshop and Conference vol II, EDK, Paris, France, pp 616618
44. Schlosser M, Strebelow M, Wassmuth R et al (2002) The Karlsburg type 1 diabetes risk study of a normal schoolchild population: association of beta-cell autoantibodies and human leukocyte antigen-DQB1 alleles in antibody-positive individuals. J Clin Endocrinol Metab 87:2254-2261

45. Levy-Marchal C, Tichet J, Fajardy I, Gu XF, Dubois F, Czernichow P (1992) Islet cell antibodies in normal French schoolchildren. Diabetologia 35:577-582

46. Reijonen H, Vahasalo P, Karjalainen J, Ilonen J, Akerblom HK, Knip M (1994) HLA-DQB1 genotypes and islet cell antibodies in the identification of siblings at risk for insulin-dependent diabetes (IDDM) in Finland. J Autoimmun 7:675-686

47. Pugliese A, Gianani R, Moromisato R et al (1995) HLA$D Q B 1^{*} 0602$ is associated with dominant protection from diabetes even among islet cell antibody-positive first-degree relatives of patients with IDDM. Diabetes 44:608-613 